\title{
Paradoxical increase in nasal airway resistance following a topical nasal decongestant spray*
}

\author{
Neela M. Doddi and Ronald Eccles \\ Common Cold Centre, Cardiff University, Cardiff, United Kingdom
}

Dear Sir,

Nasal obstruction is a very common problem associated with common cold and topical nasal decongestant sprays are effective symptomatic treatments causing a decrease in nasal airway resistance (NAR) ${ }^{(1)}$. We wish to report a case of paradoxical increase in NAR following application of a nasal decongestant spray (xylometazoline hydrochloride $0.1 \%$ w.v.). As a part of our research on the relationship between the Nasal Index and NAR, we recorded the NAR of a healthy male (Asian Indian aged 25 years, nasal index 76) using posterior rhinomanometry, before and 30 minutes after application of the topical nasal decongestant. This patient has no medical problems, no nasal allergies and no apparent nasal problems. On application of the nasal decongestant to each nasal passage his total NAR increased from 0.177 to $0.203 \mathrm{~Pa} / \mathrm{cm}^{3} \mathrm{sec}$ indicating a congesting effect of the decongestant. Because of the unusual response, the subject was recalled three weeks later and the application of the topical nasal decongestant was repeated, and on this occasion NAR again increased from 0.146 to 0.162 $\mathrm{Pa} / \mathrm{cm}^{3} / \mathrm{sec}$. In the same study, 59 healthy subjects responded to the same nasal decongestant with a decrease in NAR. A survey of the literature has not found any similar case report, although in large clinical trials on topical nasal decongestants, we have occasionally observed similar cases of a paradoxical increase in NAR. The explanation for this paradoxical response to a topical nasal decongestant is unknown, although the rebound congestion associated with chronic abuse of topical nasal decongestants (rhinitis medicamentosa) is well documented $^{(2)}$.

\section{AUTHORSHIP CONTRIBUTION}

Mr N.M. Doddi, as an ENT Research Fellow, has written this letter after observing the results of his research on the 'Relationship between Nasal index and nasal airway resistance'. This letter and the research project is supervised by Professor R. Eccles at the Common Cold Centre, Cardiff University.

\section{CONFLICT OF INTEREST}

No conflict of interest.

\section{REFERENCES}

1. Eccles R, Eriksson M, Garreffa S, Chen SC. The nasal decongestant effect of xylometazoline in the common cold. Am J Rhinol. 2008; 22: 491-496.

2. Scadding GK. Rhinitis medicamentosa. Clin Exp Allergy 1995; 25: 391-394.

\author{
Mr Neela Mouli Doddi \\ ENT Research Fellow \\ Common Cold Centre \\ Cardiff University \\ Cardiff \\ CF10 3AX \\ United Kingdom
}

Fax: +44-(0)29-20-874 093

Email: dnmouli@yahoo.co.uk 